http://dx.doi.org/10.12795/RAA.2018.14.10

\title{
DERIVA DEL GÉNERO / ESTABILIDAD DE LOS SEXOS ${ }^{\star 1}$
}

\author{
Nicole-Claude Mathieu
}

"I don't know about the women's mouvement. It's not my goal, it's not my intention. This is not about me being a woman but about me being a human being"2.

"No conozco el movimiento de mujeres. No es mi objetivo, no es mi intención. Para mí la cuestión no es ser una mujer, sino un ser humano" (cursivas mías). Esta respuesta de Madonna a Norman Mailer, antifeminista de guardia, me parece particularmente significativa: 1) porque es típica de la mayoría de las mujeres que no quieren, o que ya no quieren, oír hablar de feminismo; 2) porque también es típica de las mujeres homosexuales que prefieren trabajar al lado de los hombres en los movimientos de liberación 'gay'; y 3) porque paradójicamente la expresión "ya no se trata de ser estigmatizada por ser esto

*Traducción de Lourdes Méndez con la colaboración de Jules Falquet.

1. *Texto a partir de una intervención en la conferencia Erotisme et Pouvoir organizada por Michel Dion con los autores del libro dirigido por Cathy Schwichtenberg, The Madonna Connection (1993), París, IRESCO, 11 de febrero de 1994. Publicado en Michel Dion (dir) Madonna. Erotismo y Poder, Eds Kimé, "Le sens de l'histoire", Paris, 1994, pp. 54-70. [NdT: Texto incluido en la compilación de artículos de Nicole-Claude Mathieu (2014) L’Anatomie Politique 2. Usage, déréliction et résilience des femmes. Paris: La Dispute].

2. Madonna, entrevista con Norman Mailer en Esquire, the Magazine for Men, agosto 1994. Hay que subrayar que a lo largo de toda la entrevista Mailer no logra que Madonna diga una sola palabra en contra del movimiento feminista. Ante su observación de que el movimiento "femenino" (female) no dejaría ningún lugar a un compromiso con los hombres, incluso le responde: "en algún sitio hay que empezar". 
o aquello, sino de ser un ser humano", también expresa el objetivo de las protestas más radicales de las minorías oprimidas.

El problema está en que para alcanzar ese loable objetivo existen diferentes estrategias según se quiera ignorar la propia identidad minoritaria, o bien agarrarse a ella para que se reconozca como equivalente a la de los dominantes, o bien constituirla como fuerza política para destruir la relación de poder que la ha creado y, por lo tanto, destruirse al mismo tiempo que la otra categoría. Esas estrategias no son equivalentes y algunas no alcanzarán su objetivo ya que todo depende de lo que se entienda por la palabra "mujer" (y "hombre"). Y lo que se entienda por "deconstruir" y por turbar, las categorías. La cuestión reside en saber que las cartas pueden haberse enturbiado antes y fuera del juego pero que en el juego, si no se han cambiado las reglas, el Rey siempre es más fuerte que la Reina.

Mi intención aquí no es, en modo alguno, atacar a Madonna, cuyo inflexible valor reconozco, sino preguntarme sobre la corriente de pensamiento en la que se inserta. Tal y como ha dicho con gran exactitud en su exposición Cathy Schwitchtenberg ${ }^{3}$ Madonna, al menos en sus últimos espectáculos, se encuentra en la confluencia entre la teoría "queer" americana de origen homosexual y el feminismo posmoderno, que coinciden en su pretensión de subvertir las categorías fijas del sistema heterosexual y racista (homo/ hetero, hombre/mujer, blanco//negro, amarillo, etc.,). Madonna sería una "metáfora intergénero" que, "sobre-significando el género", desplazaría los significantes. Veremos que la cuestión está en saber si los significados (las categorías sociales de sexo) resultan modificados, lo que equivale a interrogarse sobre los límites que las condiciones sociales objetivas imponen a una metáfora $y$, correlativamente, a preguntarse sobre la posible incidencia de una metáfora sobre la "realidad".

Realidad, palabra particularmente detestada por el posmodernismo, que considero como un nuevo obscurantismo, y particularmente peligroso bajo la forma que adquiere en los Women's studies norteamericanos, no solo en crítica literaria ${ }^{4}$ y en historia, sino también en etnología. Va de la mano de un relativismo extremo tendente a prohibir toda generalización transcultural o transclase sobre las relaciones entre los sexos en nombre de las infinitas diferencias culturales o subculturales entre las "mujeres".

Puesto que en el feminismo posmoderno solo se habla de mujeres. Según los textos y contra-textos, los momentos y contra-momentos, o bien se nos dice que hay que deconstruir la categoría mujer (dado que al parecer el anterior feminismo la habría "esencializado"). Recordemos, no obstante, que gran parte de ese movimiento quiso reunir a las mujeres en contra de su esencialización, es decir, de su naturalización en y

3. Publicado en Michel Dion (dir), op. cit., 1994.

4. El colmo de la sofisticación retórica habiéndose alcanzado en las obras de Judith Butler (1990 y 1993). 
por la relación de poder impuesta por los hombres), pero en ese tipo de "feminismo" se cuidan mucho de hablar de los hombres, no se sabe si existe una categoría "hombres", solo se habla de lo masculino. O bien se nos dice que hay que realzar (enhance) esa categoría "mujer", darle fuerza, "poder" o potencia (power/empowerment), pero nunca se habla de dar a las mujeres la fuerza de defenderse de algo, y todavía menos del poder de los hombres ${ }^{5}$.

A pesar de que esos discursos (deconstruir o reforzar la categoría mujer) parezcan contradictorios, tienen un punto en común: el psicologicismo y el abandono del análisis de las relaciones sociales concretas. Así, no se interesan más que por el gender, al que solo se da un contenido simbólico, representacional, y por el "cuerpo" individual que finalmente se representa como puro dato anatómico, incluso cuando se pretende "desnaturalizarlo". Esto me da la sensación de una fruta de la que solo se vería el exterior, la peladura por una parte y el hueso por otra. La peladura: los aspectos simbólicos/imaginarios de la oposición de género masculino/femenino, de ahí el interés por el espectáculo de la diferenciación vestimentaria y por lo tanto por el travestismo, de ahí también el interés psicoanalítico por "desplazar" el famoso falo. El hueso duro: el cuerpo anatómico, de ahí el interés por la diferencia sexual y el deseo de una diferenciación de las sexualidades. Lo que se olvida en todo esto es la carne del fruto, el centro, lo que constituye al fruto en fruto y lo hace comestible -y en este caso incomestible bajo su actual forma-, la realidad de las relaciones cotidianas entre hombres y mujeres. Lo que se olvida es el sexo, no en el sentido de sexualidad, sino en el de categorización biológica que sigue funcionando socialmente -el sexo social.

El posmodernismo me parece un nuevo nominalismo, un ombliguismo individualista. No es la muerte del Sujeto, es la muerte del sujeto político, relacional. A pesar de su pretensión de "situar" los discursos (cierto que solo con relación a... otros discursos), es la muerte de todo pensamiento sociológico e histórico - un nuevo oscurantismo, vayaque me parece particularmente grave cuando se trata de la situación de las mujeres. Como dice Michèle Riot-Sarcey (1993: 6), "cierto posmodernismo reorienta la dominación como fenómeno social (es) hacia juegos epistemológicos".

Para iniciar una reciente conferencia sobre el concepto de género en la reflexión feminista, me sentí obligada a realizar un pastiche de esos oscuros juegos (de palabras) de los posmodernos, que me permito reproducir aquí:

5. Para visiones críticas sobre la sorprendente "deconstrucción” de la categoría mujer, ver Stevi Jackson (1992), y sobre Madonna y el juego con el "poder”, ver Elaine Hawkins (1992).

6. Se encontrarán en la misma obra, Féminismes au présent, buenas críticas sobre la relación feminismo/ posmodernismo, en especial los artículos de Françoise Collin (1993) y de Eleni Varikas (1993). 
"Pienso que ellos con sus ellas no renegarán de la palabra oscurantismo ya que ellos con sus ellas (sus ellas/alas, es con lo que vuelan y nos re-roban la palabra) ${ }^{7}$ están contra el racionalismo de la Ilustración. Salgo agotada, e incluso atontada, de diez días de zambullida en los fluidos del posmodernismo. Sin embargo casi he obtenido un efecto benéfico aunque perverso -quería decir perverso luego benéfico- (y perdonen que diga "yo"; quería decir: véanme como la superficie corporal, el lugar de paso en el que se actúa, se performa, la repetición de las normas regulatorias de la perversidad posmoderna), un efecto benéfico, pues, en esto que me ha venido a la mente: puesto que ya no hay Yo, ni Yo/mi. Yo (tampoco mi) irá a exponer. ¡No se expondrá! Discúlpenme si mi decisión de presentarme ante ustedes a pesar de todo, situada sin duda en algún viejo resto de oposición binaria globalizante, totalitaria y occidental (tipo moralidad/inmoralidad hacia las personas que me han invitado a hablar), si mi decisión va a imponeros mi logos, por supuesto situado en el falo-logos, que en consecuencia me empeñaré en cortar lo más pronto posible para dejar sitio a la infinita diversidad de las diferencias siempre en trance de diferir (siempre diferAntes) que no dejarán aquí, espero, de traducirse en actos discursivos y prácticas significantes en la exquisita performatividad de lo que, en tiempos prehistóricos, se llamaba una discusión. Gracias por seguir todavía ahî".

Gracias por seguir todavía ahí para quelleguemos a Madonna. Una cosa es la interpretación que hacen los intelectuales y/o los movimientos políticos, otra lo que hace Madonna y los límites que no puede franquear en los medios escénicos y mediáticos que utiliza, y otra lo que su público entiende y retiene.

Lo que quiere, aparentemente: transcender las oposiciones (y las opresiones) de sexo y raza para llegar a una comunión de toda la humanidad. "Amaos los unos a los otros", dijo Cristo, y ella lo retoma, pero para ella el mensaje moral de la comunión espiritual también pasa, y sobre todo, por la comunión física, una especie de comunismo sexual en el que se mezclan las categorías "sexuales" al igual que las "de género" y las "raciales".

\section{SEXUALIDADES MULTIPLES...}

La parte del Girlie Show (rodado en Sidney en 1993) en el que Madonna emite su mensaje de amor universal bajo forma de apología de los amores (sexualidades) múltiples es la canción "Why it's so hard to love each other? Why it's so hard to love?". Es también el momento en el que la homosexualidad femenina se escenifica más explícitamente puesto que la secuencia debuta con Madonna y dos bailarinas (las tres vestidas "de mujeres") deseándose y acariciándose sobre una plataforma sobreelevada. Después, sobre la letra "love your brother, love your sister", bailarines y bailarinas representan escenas de amor

7. Nota de la traductora: en francés "elles" (ellas) y "ailes" (alas) suena igual. Lo mismo sucede con "voler" (volar) y "voler" (robar). 
colectivo, hombres y mujeres, hombres y hombres, mujeres y mujeres. Reténgase que los gemidos amorosos solo provienen de las voces de las mujeres -lo que reproduce una característica del actual estado de las relaciones heterosexuales (a menudo es imposible distinguir si tu vecina grita de placer o de sufrimiento, lo que hace aún más impresionante el silencio de los hombres; aún más cuando se sabe que para la mayoría de los hombres es erótico forzar a una mujer). Algo muy explotado en las películas pornográficas, e imitado con conocimiento de causa por las prostitutas en su trabajo. La canción acaba sobre la plataforma de nuevo sobreelevada presentando, tras Madonna, a un hombre muy alto que rodea tiernamente con sus brazos a dos mujeres más bajas.

Si el mensaje podría interpretarse como antirracista en la medida en que el hombrereferente ya no es blanco sino negro y una de las mujeres es blanca y la otra negra (pero es cierto que, tal y como ha señalado sobre otros aspectos Thomas Nakayama ${ }^{8}$ ciertos Afroamericanos podrían interpretarlo a la inversa, como una sobresexualización de los negros) se retendrá en cambio que la homosexualidad ha desaparecido en beneficio de un multipartenariado [multiparteniarat] masculino heterosexual... (podría haberse presentado al final una mujer y dos hombres). Además diría que la homosexualidad femenina ha desaparecido todavía más que la masculina (paradójicamente dado que la primera audacia de Madonna fue realzar el lesbianismo), puesto que dos mujeres para sí mismas al principio, al final se transforman simbólicamente en dos mujeres (aunque estas fueran homosexuales) para un hombre.

Por lo tanto el público puede estar tranquilo. Se sabe, por una parte, lo mucho que los hombres aprecian las llamadas escenas lesbianas en las producciones pornográficas y en las prácticas a tres (o a más). Por otra parte, la expresión de "comunidad sexual" que he utilizado antes recordará no solo que es un fantasma principalmente masculino, sino que en la realidad tal comunidad sexual es la puesta a disposición de todas las mujeres, o de algunas, a merced de la voluntad de los hombres. Esto es particularmente claro en cierto número de sectas espirituales-comerciales, o en los grupos de skin-heads, por tomar ejemplos extremos, pero tampoco es ajeno a formas de organización de la sexualidad consideradas como normales (según las épocas y las sociedades), como las relaciones sexuales en los grupos de jóvenes donde son los chicos los que deciden y eligen, las "orgías" de adultos modernos (o posmodernos) en las que generalmente el dinero proviene de los hombres, las formas más habituales de prostitución, o bien la poliginia (varias mujeres que están simultáneamente bajo el control de un hombre en el matrimonio), muy expandida en el mundo.

Esto para decir que sean cuales sean las intenciones subversivas de Madonna, en el actual estado de la imaginación erótica, por ahora basada sobre el poder real de los hombres sobre las mujeres, parece difícil imaginar y aún más presentar al gran público un erotismo

8. Thomas Nakayama, en Michel Dion (dir) (1994). 
"para todos y todas indistintamente" que no sea re-interpretable como un erotismo al servicio/beneficio de los hombres.

Planteémonos la cuestión del público de Madonna, y sobre todo del público joven, el que está iniciando la vida sexual y que sin duda es el más dependiente de las normas sociales heterosexuales: la mujer debe hacerse deseable, el hombre decide si lo es; dicho de otra manera, la mujer debe inducir el deseo del hombre, producirse para el hombre, no debe producir su propio deseo, "producirse ella misma", como dice y teme Jean Baudrillard" de Madonna. Que Madonna aconseje explícitamente a las mujeres que "se expresen" (Express yourself), que se afirmen como seres autónomos en la sexualidad, hace que sus fans y ciertos analistas la consideren como "un modelo de rol positivo para las adolescentes"10. Pero ¿de qué positividad se trata?

Algunos ecos que he tenido sobre juicios favorables entre jóvenes Franceses (nivel BEP certificado de estudios profesionales, que devendrán secretarias, dependientas, peluqueras, agentes de producción, etc.,) sobre los clips de Madonna (nótese que no pueden pagarse la entrada a los espectáculos) son, del lado de los chicos, que no tiene miedo de exhibirse, que es sexualmente provocadora, del lado de las chicas, que baila bien, que se baila bien con sus músicas, y que parece "dominar a los hombres".

Pero ¿qué debemos entender en esas últimas palabras? Todo induce a pensar que no se trata de lo que tanto temen los hombres del feminismo (van a tomar el poder sobre nosotros, -ver la entrevista de Mailer con Madonna-, y, poseyendo los hombres el poder real, saben de lo que hablan y tendrían razón de tener miedo si tal fuera el fin del feminismo), sino más bien del famoso y muy antiguo y fantasmático "poder erótico" de La Mujer que no es exclusivo de la civilización occidental ${ }^{11}$. Una joven secretaria ante quien se extrañaban de que hubiera ido a ver una película de Madonna respondió: "es para ver cómo hace, para saber qué ropa interior debo comprar para estar sexy, porque acabo de conocer a un hombre" (en sus dos anteriores relaciones había sido golpeada, una de las veces porque se negaba a ser sodomizada -ahí se ve cómo las jóvenes pueden "dominar" a los hombres).

9. Jean Baudrillard, en Michel Dion (dir) (1994).

10. Indicado por Laurie Schulze, Anne Barton White y Jane D. Brown (1993) "A sacred monster in her prime: audience construction of Madonna as low-other", en Cathy Schwichtenberg (dir) The Madonna connection: representational politics, subcultural identities, and cultural theory, pp. 15-38, Westview Press, Boulder.

11. Ver por ejemplo el libro de Fatna Aït Sabbah (1982) en el que explora el discurso erótico del patrimonio musulmán (la mujer como omnisexual) al mismo tiempo que el discurso del poder sobre la realidad, el del islam legal ("la belleza" de las mujeres como silencio e inmovilidad. "¿Por qué un cuerpo de hombre es abrazado por el deseo de acoplarse con un cuerpo de mujer que se declara sumiso y dominado?, se pregunta entre otras cosas. Habiendo escrito el libro para "defenderse de la opresión y la estupidez", no es de extrañar que eligiera un pseudónimo. 
En lo que concierne a esas jóvenes francesas hay que retener que en general no pueden entender las letras en inglés de las canciones de Madonna. Pero en Inglaterra se ha hecho una encuesta (Jane Rowlye, 1994) entre chicas blancas de entre 14 y 16 años definiéndose como heterosexuales, y de un medio (clase obrera) similar al que acabo de evocar. $\mathrm{Su}$ discurso en cuanto a la asimetría de las relaciones entre los sexos y la imposibilidad concreta para esas chicas de elegir a Madonna como "modelo" en la vida cotidiana, es de una lucidez que deberían envidiarles muchos universitarios.

Por una parte, "resisten" a Madonna, conscientes de que sus compañeros de clase sobre todo ven en ella un objeto sexual, y eso las vuelve a enfrentar con la objetualización, al acoso, a las provocaciones e insultos sexuales que soportan cotidianamente por parte de los chicos, en especial en la escuela. Por otra parte, algunas la ven como una mujer fuerte con relación a los hombres, una mujer libre que se acuesta con quien quiere, pero "yo nunca podría hacerlo" (no se atreven ni a tener condones encima, ya que..." todo el mundo dirá que eres una guarra, una puta $[a \mathrm{slag}]$ )". Por tanto, necesidad para las chicas de velar sobre su reputación mediante lo que la autora denomina "auto-vigilancia". En resumen, se reconoce aquí el eterno doble estándar moral según el sexo y el doble constreñimiento psicológico en el que toda idea de "liberación sexual" coloca a las mujeres ya que ellas no son para los hombres más que objetos de los que apropiarse.

Madonna imagina un erotismo generalizado, enturbiadas todas las categorías precedentes. Pero en una sociedad en la que las relaciones de poder entre sexos y razas están, como todas las relaciones de poder, ancladas en lo económico, lo jurídico, lo cultural, y perpetuadas por la violencia, verbal y física, ante el menor desliz de los dominados y de las dominadas ¿puede inventarse realmente un erotismo "para todos", igualitario? Imaginarlo ya es difícil: creer, como el movimiento queer, que puede realizarse "desplazando" las categorías de pensamiento sin atacar sus raíces es inconsecuente, ilógico y conlleva riesgo de recuperación ${ }^{12}$. Hace falta, se nos dice, "llevar los márgenes al centro"... Eso puede parecer insensato en el plano de las definiciones... puesto que es tomar un conjunto (minorías/mayoría) con definición dialéctica jerárquica (vertical) por un tablero de ajedrez (horizontal) en el que los cuadrados blancos y negros son distintos pero equivalentes, y en el que cualquier peón, blanco o negro, siempre puede llevarse al centro. Esa visión de las minorías, y con mayor amplitud de todo grupo social, parece propia del pensamiento común americano ${ }^{13}$. Pero quizás haya otra manera de

12. Para una crítica de la política del movimiento queer ver Julia Parnaby (1993) “Queer straits", Trouble and Strife (26): 13-16.

13. Sobre una definición radicalmente diferente de la noción de grupo social y de sociedad en USA y en Francia y sus consecuencias sobre las teorías feministas ver el artículo de Gail Pheterson (1994) "Group identity and social relations: Divergent theoretical conceptions in the United States, the Netherlands and France", The European Journal of Women's Studies I (2): 257-264. 
considerar la cuestión: suponiendo que sea posible llevar ciertos márgenes al centro, ¿no será porque, desde cierto punto de vista, ya estaban allí?

Es lo que vi comparando el lugar estructural que, respectivamente, ocupaban la homosexualidad femenina y la masculina en diferentes sociedades (Nicole-Claude Mathieu 1989) ${ }^{14}$. Es cierto que en numerosas sociedades se desprecia e incluso se reprime a las personas homosexuales. No obstante, a nivel institucional, la homosexualidad masculina puede utilizarse a mayor o menor escala para permitir el acceso de los hombres a la virilidad, es decir, a la confirmación de su estatus de género en oposición jerárquica al estatus femenino. Esto es bastante conocido para la Grecia clásica, en Esparta y Atenas. Pero sucede lo mismo, por ejemplo, con la homosexualidad ritual durante la iniciación de los niños en las sociedades melanesias estudiadas por la etnología. Más cerca de nosotros, pero con el mismo sentido, puede considerarse que numerosas formas de homosexualidad o de homosocialidad masculina (cuando se afirma que la homosexualidad masculina no existe), son expresión de la fraternidad viril contra las mujeres, que expresa y refuerza la jerarquía de los géneros (véase los bares 'cuero' homosexuales, los equipos de deporte masculinos, por no hablar de la ideología nazi...).

Otro modo de institucionalización de la homosexualidad masculina existía en África entre los Azande, a través de la práctica totalmente oficial de los matrimonios entre hombres en la clase superior de los guerreros. Los jóvenes de esa categoría estaban faltos de mujeres dado que los mayores acumulaban mujeres (gran poliginia). Mientras que esperaba hasta encontrar una mujer-esposa, cada guerrero podía casarse con un chicoesposa que le debía los mismos servicios sexuales y económicos que una mujer (tomaba pues el género mujer) pero que devendría él mismo más tarde un hombre-marido con un chico-esposa, antes de encontrar mujer, etc. Se ve que la inversión de sexo no es obligatoriamente una inversión del género.

Todo esto para decir que la homosexualidad de los hombres no contradice necesariamente el sistema heterosexual que él, sin embargo, sí que está rigurosamente destinado a controlar a las mujeres con el fin de asegurar la reproducción forzosa (véase Paola Tabet, 1985, para las más diversas sociedades) -la llamada maternidad-pero también al mismo tiempo, el trabajo necesario para el cuidado material de los hombres y de sus dependientes ${ }^{15}$. Ya que el "género" no es solo simbólico. La oposición psicológica, sexual

14. Para no recargar la bibliografía, en este texto no se incluyen las referencias etnológicas. Naturalmente están en el artículo citado.

15. Véase para las sociedades occidentales, Colette Guillaumin (1978) "Pratique du pouvoir et idée de Nature (I); "Lappropiation des femmes (II) Le discours de la Nature", en Questions féministes (2-3) sobre la apropiación privada y colectiva de las mujeres; y Christine Delphy y Diane Leonard (1992) Familiar explotation. A new analysis of marriage in contemporary Western societies, Cambridge: Polity Press y Blackwell Publishers, sobre la familia como sistema económico. Y para el trabajo "familiar" (y otro) de las mujeres en las actuales sociedades del tercer mundo, ver por ejemplo Seteney Shami et al. (1990). 
o vestimentaria entre masculino y femenino no es más que el epifenómeno del género en su funcionamiento económico y social -es decir la bipartición jerárquica de las funciones y de las tareas entre dos grupos sociales que elige como criterio el sexo de los individuos.

Por eso, mientras que la organización social esté controlada por el grupo de los hombres, la homosexualidad femenina es más peligrosa. Podría darles a las mujeres la idea de que se puede contrarrestar el poder de los hombres (algo explícitamente dicho por los hombres Azande, y se reconocerá que no son los únicos que lo temen en el mundo). Muy pocas veces se institucionalizan las relaciones reales entre mujeres, y nunca forman parte del sistema simbólico global que estructura el mundo y la sociedad. Generalmente se silencian, no se "visibilizan" (además se tendrá en cuenta que si entre los Azande eran relativamente oficiales, necesitaban ser autorizadas por el marido). Por último, para volver al matrimonio y a la procreación femenina, es destacable que incluso en una de las escasas sociedades (los Swahili de Mombasa, en Kenia) donde, al parecer, se acepta bastante bien la vida en pareja homosexual, tanto para las mujeres como para los hombres, las mujeres solo pueden hacerlo tras haber estado casadas, es decir, tras haber procreado. Es cierto que hoy en día, en las sociedades occidentales, incluso las lesbianas solteras se hacen embarazar..., pero el matrimonio sigue siendo un valor seguro (creo que el 70\% de los jóvenes recientemente interrogados por M. Balladur colocan a la familia en el primer lugar). Por lo tanto ¿vamos a extrañarnos de que desaparezca la pareja lesbiana al final de la secuencia de Madonna de la que he hablado?

\section{TRAVESTISMOS, TRANSVESTISMOS, TERCEROS GÉNEROS...}

Además de las categorías de sexualidad, Madonna también quiere enturbiar las categorías de "género" (gender), en el sentido simplificado de la apariencia de lo masculino y lo femenino, utilizando el travestismo, y luego el travestismo del travestismo (debo reconocer que a veces con el suficiente éxito como para que, al menos en la versión fílmica del Girlie Show, cueste trabajo reconocer las categorías de sexo -digamos los hombres y las mujeres "biológicos"). La cuestión que puede plantearse en lo que respecta al travestismo es la de saber si es una subversión de los roles de género o lo que denomino una "solución normada" a las inadecuaciones.

Me he interesado (Nicole-Claude Mathieu, 1989) por diferentes fenómenos de passing de género (y de sexo) no solo en las sociedades occidentales (travestis y transexuales modernos), sino también en otras sociedades ya que hay que recordar que en el campo de la travesía de los géneros [cross-gendering], iino somos los primerosii

En las sociedades tradicionales la forma más conocida y difundida de travestismo es lo que los etnólogos llaman ritos de inversión, ceremonias colectivas en las que los hombres se disfrazan y/o se comportan como mujeres e inversamente con, por lo demás, un aspecto de caricatura y parodia muy próximo al de la teatralización de los espectáculos 
modernos de travestis y a los de Madonna. Una cosa que me llamó la atención en esos ritos periódicos o circunstanciales, se trate de los ritos del Carnaval en Cerdeña o del famoso Naven de los Iatmul de Nueva Guinea, es que la caricatura que los hombres hacen de las mujeres es mucho más fuerte que la que las mujeres hacen de los hombres. Me parece que esta asimetría en la representación simbólica de un grupo de sexo por parte del otro está directamente ligada a la jerarquía que, de hecho, existe entre ambos. Puede permitirse caricaturizar al inferior. Además, las ceremonias de desorden momentáneo (un día al año, por ejemplo) se llevan a cabo para reafirmar lo bueno que es el "normal" orden de los sexos y los géneros.

Nos dice Cathy Schwichtenberg que Madonna es "una mujer que se disfraza de hombre que se disfraza de mujer". ¿Está por lo tanto obligada a pasar por un hombre para caricaturizar la feminidad? ¿Quiere eso decir que para turbar las categorías de género, sería insoportable en el plano simbólico que sea simplemente una mujer la que se disfraza de hombre?

Me pregunto si el acaparar lo femenino por parte de los hombres en el nivel de los juegos simbólicos no es tanto más posible que imposible les resulta en la realidad rebajarse hasta lo femenino. Algunas poblaciones como los Gimi de Nueva Guinea han llevado el acaparamiento hasta el extremo puesto que en su representación del mundo hay un único sexo, el masculino; pero en la vida cotidiana los dos "géneros" están perfectamente marcados y reposan sobre la jerarquía de los grupos de sexo.

En nuestras sociedades las mujeres han obtenido la posibilidad de llevar pantalón (pero no el salario que va con él), pero es imposible para un hombre "normal" salir con falda a la calle. Lo que significa una falda -quiero decir una mujer social- está perfectamente claro si, por ejemplo, se tiene en cuenta el cartel-reclamo de una revista pornográfica asociada a un sex-shop parisino que apareció durante la primera semana de septiembre en los escaparates del distrito V de París. Se ve a un hombre desnudo, arrodillado, con los brazos un poco levantados como un perro que pide que le den un terrón de azúcar, sobre el que está montada, sujetándole con riendas (él tiene la correa en la boca), una mujer con botas y vestida de cuero. Sobre la foto, gran titular en rojo: "las dominadoras, esas nuevas libertinas que someten a los hombres". Hasta ahí, nada nuevo, tendríamos ganas de responder. Más interesante, sino más novedoso, es el título colocado al lado del cuerpo del hombre: "Feminizad a vuestro marido, él no espera más que eso". No se puede decir mejor que en nuestra sociedad como en otras, "feminidad" igual a "de rodillas, con arneses y pidiendo su terrón de azúcar".

La niña que se pasea por la calle podrá sacar todas las conclusiones (por desgracia inconscientes) necesarias para su educación, la mujer no mirará el cartel. Pero el niño y el hombre no tendrán que preocuparse ya que el hombre del cartel no está realmente sujetado con el arnés, todo está colocado sobre él de forma flotante. (Además, en las 
revistas pornográficas, y con razón, nunca se fotografía a los hombres en posiciones tan cosificadoras y humillantes, como a las mujeres. Es el momento de recordar lo que en 1913 decía la novelista inglesa Rebecca West (citada por Susan Faludi, 1993: 30): "Nunca he logrado definir el feminismo. Todo lo que sé es que cada vez que mi comportamiento impide que se me confunda con un felpudo, la gente me llama feminista”.

Los hombres están dispuestos a travestirse en mujer, es incluso divertido en la intimidad, como fantasía erótica, o públicamente, como espectáculo, pero no tienen la más mínima intención de dar el menor paso hacia la realidad reservada a las mujeres. Me han contado que en el Norte de Grecia, todavía en la actualidad, durante el día anual de la inversión de los roles de sexo, las mujeres, antes de ir al bar para beber y conversar en lugar de los hombres, les dejan una lista de los trabajos que hay que hacer mientras que estén en casa en el lugar de las mujeres. Parece que al final de la "fiesta", no se han llevado a cabo la totalidad de los trabajos femeninos ("demasiado duros", dicen los hombres). Y sin embargo esos mismos hombres dirán, aludiendo a ese día: “iEl 8 de enero, es la ginecocracia!".

Se ve por lo tanto que el travestismo (y con mayor razón la inversión de tareas) tiene sus límites, que es asimétrico puesto que está "informado" por relaciones concretas de poder entre los sexos. ¿Pero qué sucede con los travestismos, si con ese término designamos el pasar de un género a otro no ya ocasional o estacionalmente, sino de forma relativamente estable en aquellos individuos que lo practican?

El caso de los Inuits (Esquimales) es uno de los más interesantes porque se encuentran no solo cambios de género, sino de sexo (lo que en cierta medida los acerca al pensamiento de los transexuales modernos). Exponer aquí las complejidades sería excesivamente largo. Digamos solo -en nuestros términos- que algunas chicas serán educadas desde edades tempranas como chicos, y algunos chicos como chicas, porque se considera que son del otro sexo. Todo esto da infinitos matices en el "tercer sexo" y en los passing de género, y hace que se les atribuya poderes espirituales particulares. Solo retendré aquí que al parecer esos poderes son menos "poderosos", si me atrevo a decirlo así, entre los individuos (inicialmente) mujeres que en los (inicialmente) hombres.

Pero vengamos a los "berdaches" amerindios (América del Norte), aunque solo sea porque actualmente, en Estados Unidos y Canadá, hacen soñar a una parte de la comunidad homosexual, incluidos los homosexuales amerindios, sobre la posibilidad de un "tercer género" o de un "género mixto". Se trataba de hombres y de mujeres que, a título personal, decidían adoptar el género, es decir los vestidos, actividades y estatus social del otro sexo, y eso estaba ratificado por su sociedad. Durante mucho tiempo, en etnología, se ha llamado a ese fenómeno "homosexualidad institucionalizada" dado que esas personas se casaban o tenían relaciones sexuales con personas del mismo sexo, pero las nuevas interpretaciones señalan que se trata más bien de una "heterosexualidad social" o de una 
heterosocialidad puesto que en esas parejas los géneros se mantenían opuestos siguiendo la norma heterosexual: la mujer que había devenido hombre social se casaba con una "verdadera" mujer (en sexo y en género), el hombre devenido mujer social se casaba con un "verdadero" hombre. Sostengo que la verdadera homosexualidad habría consistido, por ejemplo, para un hombre-en-mujer, en casarse con otro hombre-en-mujer, algo no constatado. Aún así, su sociedad atribuía a esos berdaches poderes espirituales fuera de lo común (un poco como entre los inuits) por haber atravesado los géneros.

Pero hay que subrayar que, a pesar (de lo que he llamado) su común "transgresión del sexo por el género", la situación de los berdaches hombres y mujeres no era para nada simétrica y eso en función de su sexo de origen ${ }^{16}$. Así se ve a una mujer que ha devenido hombre social ir a enfrentarse con el amante de su esposa, como cualquier hombre normal, y... recibir amenazas de violación. Por lo tanto existen límites al pretenderse hombre. En cambio, los hombres que habían devenido mujeres sociales eran considerados como mucho mejores en las tareas femeninas que las mujeres ordinarias (el caso inverso no está constatado). Por lo tanto siempre vale más ser biológicamente hombre que mujer. Nos dicen que el travestismo y el transvestismo "desnaturalizan el género". Pero no parece desnaturalizar el sexo, si entendemos por sexo no solo aquello que entra en juego en la sexualidad, sino el estatus material asignado a la gente sopretexto del sexo. En nuestras sociedades, y aún más en otras, la organización del sexo social sigue descansando sobre la opresión de las mujeres, y el posfeminismo no va a salvar la situación discurriendo "al lado".

Hay discursos igual de oscuros pero más divertidos que los del posmodernismo. Como este extracto del manual de un coche que alquilé antaño en Portugal. Para saber cómo cambiar una rueda (tarea masculina), consulté la versión "en francés":

"En el lado lateral del coche existe un frasco para aplicar el mono localizado en el gancho de la cobertura lateral. Asegurarse de que ese frasco nunca está obstruido. Introducir completamente el brazo elevador del macaco en el frasco. Asegurarse de que la base del macaco está sobre un suelo firme".

Un suelo firme, eso, lo había comprendido. El feminismo (?) posmoderno y el movimiento queer creen poder cambiar una rueda, pero la pendiente resbala. $Y$ cada vez que en mi casa limpio los cristales (tarea que sigue siendo femenina salvo cuando se paga: solo hay hombres lavando las vitrinas de los comercios), pienso que prefiero clarificar la economía política del género más que "turbarlo"17 con la economía. Los cultural studies

16. Señalemos también que sobre el centenar de población con berdaches censadas, sólo una treintena tenían berdaches mujeres.

17. Según el título del libro de Judith Butler, Gender Trouble. 
tienen mucho éxito en Estados Unidos pero ¿Dónde están las sociedades? ¿Dónde están las vidas de las mujeres, las que han denunciado, arriesgando su vida, Taslima Nasreen y muchas más? ${ }^{18}$.

18. Sobre el insulto posmoderno como insulto a la realidad: tras haber hablado contra los intelectuales que "firman peticiones y se van de vacaciones" (pero pasemos por alto ese detalle mezquino), Philippe Sollers (Libération, $1^{\circ}$ de agosto de 1994) aconseja a Taslima Nasreen : "No escuche usted a nadie, no confíe en nadie, ¡escápesej”. Es muy sencillo. Estás condenada a muerte, mujer en un país musulmán. Has denunciado los diversos abusos de los que eres testigo. Miles de fundamentalistas gritan contra ti en las calles. Estás escondida en algún lugar en casa de gente que arriesga su vida por salvarte. Pero no confías en nadie, abres la puerta y, iya!, has hecho tranquilamente el viaje de Dacca a Estocolmo. ¡Que insulto! A Nasreen, a sus amigos, a la realidad. 